\title{
PELATIHAN 3D PRINTING UPAYA UNTUK MENINGKATKAN KEMAMPUAN GURU SMK NEGERI DI DEPOK
}

\author{
Habibi Santoso ${ }^{1 *}$, Henra Nanang Sukma ${ }^{2}$ \\ ${ }^{1}$ Teknik Grafika, Politeknik Negeri Media Kreatif, Indonesia \\ Habibisantoso1@gmail.com, henrananangsukma@gmail.com
}

\begin{abstract}
ABSTRAK
Abstrak: Kegiatan Pengabdian Kepada Masyarakat (PKM) ini bermitra dengan Sekolah Menengah Kejuruan Negeri di Depok. Pada kegiatan pembelajaran dan praktek sangat sering mengalami kesulitan mendapatkan komponen tertentu yang jarang didapat atau dijual di pasaran. Hal ini tentunya dapat diatasi dengan menggunakan mesin 3D Printing, karena guru-guru dapat membuat sendiri komponen dengan menggunakan mesin ini. Tujuan pengabdian ini adalah untuk memberikan pelatihan pada guruguru mengenai mesin 3D printing. Pelaksanaan pada kegiatan pengabdian masyarakat kali ini dilakukan secara daring/online dalam bentuk Webinar dengan diskusi, tanya jawab, dan praktek, angket awal digunakan untuk mengetahui seberapa jauh para peserta guru memiliki pengetahuan tentang teknologi 3D printing. Hasilnya 100\% guru-guru belum mengetahui teknologi mesin 3D Printing. Setelah pelatihan didapatkan hasil angket akhir menunjukan bahwa keberhasilan memberikan pemahaman pengetahuannya mengenai teknologi 3D printing bertambah. Hal tersebut dapat dilihat dari jawaban peserta dari dari segi kebermanfaatan $83,3 \%$ setuju dan 16,7 tidak setuju, dari tingkat kepahaman peserta menjawab $66,7 \%$ dan $33,3 \%$ tidak setuju.
\end{abstract}

Kata Kunci: $3 D$ Printing, guru, Komponen

Abstract: This Community Service (PKM) activity is in partnership with a State Vocational High School in Depok. In learning and practice activities, it is very often difficult to get certain components that are rarely obtained or sold in the market. Of course, this can be overcome by using a 3D Printing machine, because teachers can make their own components using this machine. The purpose of this service is to provide training to teachers regarding $3 D$ printing machines. The implementation of this community service activity was carried out online in the form of a Webinar with discussions, questions and answers, and practice, the initial questionnaire was used to find out how far the teacher participants had knowledge of $3 D$ printing technology. The result is that $100 \%$ of the teachers do not know about $3 D$ Printing machine technology. After the training, the results of the final questionnaire showed that their success in providing an understanding of their knowledge about $3 D$ printing technology increased. This can be seen from the participants' answers in terms of usefulness $83.3 \%$ agree and 16.7 disagree, from the level of understanding participants answered $66.7 \%$ and $33.3 \%$ disagree

Keywords: 3D Printing, teacher, Component

\section{A. LATAR BELAKANG}

Saat ini salah satu teknologi yang sedang berkembang yaitu teknologi 3D Printer dengan mesin untuk pembuatanproduk bisa dilakukan dengan mudah, cepat dan mendetail.3D printer ini bisa mencetak, modelling, purwarupa /pemodelan, alat-alat peraga untuk pendidikan, modelperhiasan, alat-alat penunjang kesehatan, desain produk,mainan anak-anak dan berbagai kebutuhan untuk mencetakbentuk dalam 3 dimensi sehingga teknologi ini menjadisalah satu tren teknologi informasi dan komunikasi masakini. Hal ini dapat dilihat dari kebutuhan manusia yangsemakin lama semakin mutakhirr

Beberapa permasalahan yang sering dihadapi olehguru-guru di SMK Negeri Depok diantaranya adalah : 
1. Pada kegiatan pembelajaran dan praktek sering mengalami kesulitan mendapatkan komponen tertentu yang jarang didapat atau dijual di pasaran

2. Kurangnya pengetahuan guru mengenai mesin 3D Printing

Berdasarkan masalah mitra yang telah diuraikan di atas yaitu, guru-guru SMK Negeri Depok perlu tambahan pengetahuan tentang teknologi 3D printingteknologi 3D-printing yang merupakan proses pembuatan benda padat 3 dimensi dari suatu desain digital betujuan agar guru-guru mampu membuat sendiri komponen-komponen mesin praktikum yang sulit didapat dipasaran

Dengan demikian, solusi yang dapat ditawarkan pada mitra adalah memberikan pelatihan mengenai teknologi 3D printingdimana guru-guru SMK Negeri Depok akan diberi pengetahuan tentang teknologi 3D printing dan membuat sendiri komponenkomponen mesin praktikum yang sulit didapat dipasaran dan dapat meningkatkan keterampilan bagi guru-guru SMK Negeri Depok

Luaran dari pelatihan ini diharapkan para peserta pelatihan yaitu guru-guru SMK Negeri Depok memiliki pengetahuan dan keterampilan menggunakan mesin 3D Printing serta mampu membuat komponen-komponen mesin praktikum yang sulit didapat dipasaran.

\section{B. METODE PELAKSANAAN}

Pelaksanaan pada kegiatan pengabdian masyarakat kali ini dilakukan secara daring atau online dalam bentuk Webinar dengan diskusi, tanya jawab, dan praktek. Materi diskusi berkaitan dengan pelatihan 3D Printing yang dilakukan,, manfaat pelatihan, terutama pelatihan 3D Printing secara daring ini yang akan disajikan oleh narasumber pertama. Setelah itu, kegiatan dilanjutkan oleh narasumber kedua yaitu praktek 3D printing, mulai dari persiapan desain, bahan PLC, mesin, sampai dengan praktik pengoperasian alat 3D Printing.

Pada SMK Negeri Depok, terdapat jurusan Teknik Audio Video, Teknik Pendingin dan Tata Udara dan Teknik Instalasi Tenaga Listrik. Dalam kegiatan pembelajaran atau praktek sangat membutuhkan banyak komponen yang digunakan. Pada kegiatan pembelajaran dan praktek sangat sering mengalami kesulitan mendapatkan komponen tertentu yang jarang didapat atau dijual di pasaran. hal ini tentunya dapat diatasi dengan menggunakan mesin 3D Printing, karena guru-guru dapat membuat sendiri komponen dengan menggunakan teknologi 3D printing ini. Oleh karena itu pelatihan ini sangat penting dan bermanfaat untuk meningkatkan kemampuan dan pengetahuan guru-guru SMK Negeri Depok.

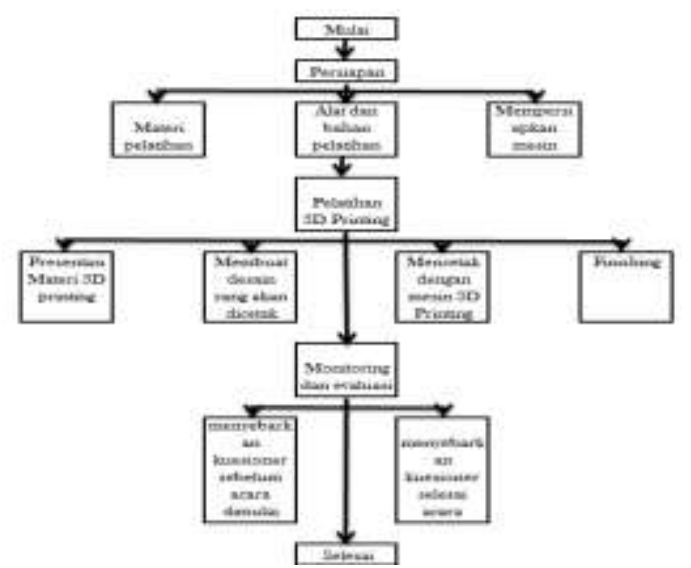

Gambar 1 Diagram Alir pelatihan

Pelaksanaan pelatihan dilaksanakan 1 kali pertemuan, pemaparan materi dilakukan melalui diskusi secara daring/online. Materi yang disampaikan adalah teknologi 3D printing agar para peserta mampu memahami teknologi 3D printing. Para peserta 
pelatihan diberikan juga waktu untuk bertanya bagi yang belum paham agar memiliki pengetahuan yang cukup mengenai media pembelajaran digital.Lalu kegiatan selanjutnya adalah melihatkan cara kerja mesin 3D printing secara online, yang mana mesin 3D tersebut sedang mencetak komponen mesin yang dimana komponen tersebut dapat digunakan sebagai komponen pengganti pada mesin praktikum yang sulit didapatkan dipasaranGunakan aplikasi Mendeley untuk menulis referensi, pilih gaya APA (Syaharuddin \& Ibrahim, 2017). Penulisan penulis tidak boleh mencantumkan jabatan (misalnya dosen pembimbing), gelar akademik (misalnya Prof, Dr, M.Pd, M.Si, M.Si, dan lain sebagainya.) atau keanggotaan organisasi mana pun (Dwiranata, 2019).

Setiap afiliasi harus dicantumkan setidaknya nama lembaga atau perusahaan dan nama negara/wilayah tempat penulis berada (Balai Informasi Sumber Daya Air DPU NTB, Indonesia). Penulis diwajibkan memasukkan alamat email (Sucipto \& Syaharuddin, 2018)

\section{HASIL DAN PEMBAHASAN}

\section{Alur dan Proses Kegiatan}

Pelatihan diberikan kepada guru SMK Negeri XY Depok yang mengacu pada permasalahan yang dirasakan oleh mitra yaitu dimana guru-guru SMK Negeri XY Depok menghadapi permasalahan terkait dengan komponenkomponen dan part-part elektronik yang sulit didapatkan sehingga menimbulkan permasalah pada saat pelaksanaan praktikum dan kurangnya pemahaman teknologi 3D Printing yang semakin berkembang, maka perlu memberikan pengetahuan tambahan pada guru-guru khususnya di bidang teknologi guna membantu guru dalam memperlancar proses pembelajaran di sekolah agar lebih efektif dan efisien.

Pada bagian ini akan disajikan kegiatan pengabdian masyarakat yang telah dilaksanakan, yaitu:

1) Proses Kegiatan Pelatihan,

2) Hasil Angket Awal dan Akhir,.

Untuk mencapai tujuan dari kegiatan pengabdian masyarakat yang dilakukan secara daring ini maka disusun jadwal kegiatan sebagai berikut:

\begin{tabular}{|l|l|l|l|l|}
\hline No & Tanggal & Waktu & Materi & Narasumber \\
\hline 1 & 18 Januari 2021 & $\begin{array}{l}13.00- \\
16.00\end{array}$ & $\begin{array}{l}\text { Presentasi Materi 3D } \\
\text { Printing }\end{array}$ & Henra Nanang \\
& & Sukma, S.T.,M.T \\
\hline 2 & 18 Januari 2021 & $16.00-$ & Penjelasan video Proses & Habibi Santoso, \\
& & 17.00 & Cetak 3D & S.T.,M.T \\
\hline
\end{tabular}

Pada pertemuan pertama, Narasumber 1, Henra Nanang Sukma, S.T.,M.T, menyajikan materi tentang media 3D Printing yang menyimpulkan bahwa teknologi 3D printing sangat dibutuhkan pada era industry 4.0 ini 3D-Printing merupakan sebuah terobosan baru dalam dunia teknologi. 3D-Printing adalah sebuah printer yang mampu mencetak benda berdimensi tiga, bukan berupa gambar atau tulisan di atas kertas. Kelebihan dari 3D-Printing adalah sangat memungkinkan untuk membuat berbagai bentuk pola rumit Hal ini dikarenakan keleluasan gerakan printing pada ruang lingkup tiga dimensi.

Berikut ini gambar penyajian materi pelaksanaan kegiatan Pengabdian Masyarakat kepada guru SMK Negeri 2 Depok : 


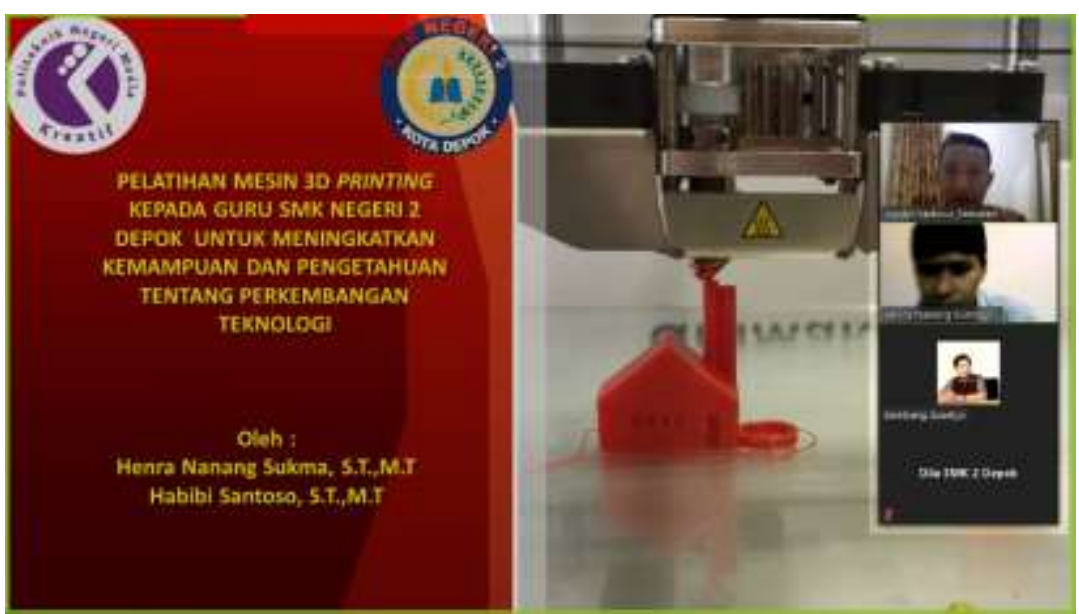

Gambar 5.1 Penyampaian Materi oleh Narasumber 1 (Sumber: screenshoot Penulis)

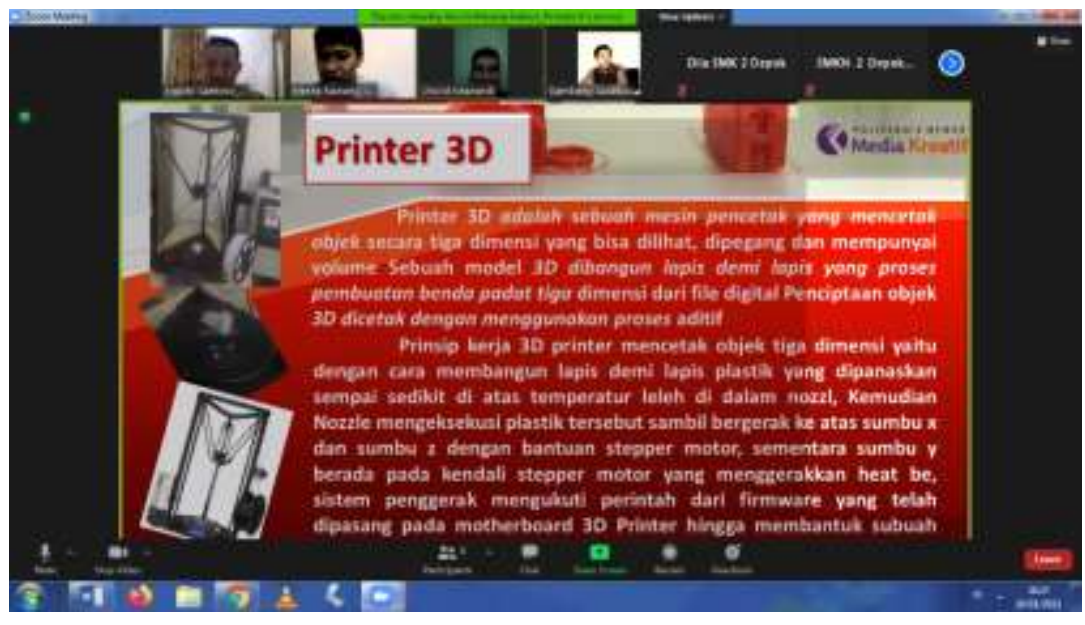

Gambar 5.2 Penyampaian Materi oleh Narasumber 1

(Sumber: screenshoot Penulis)

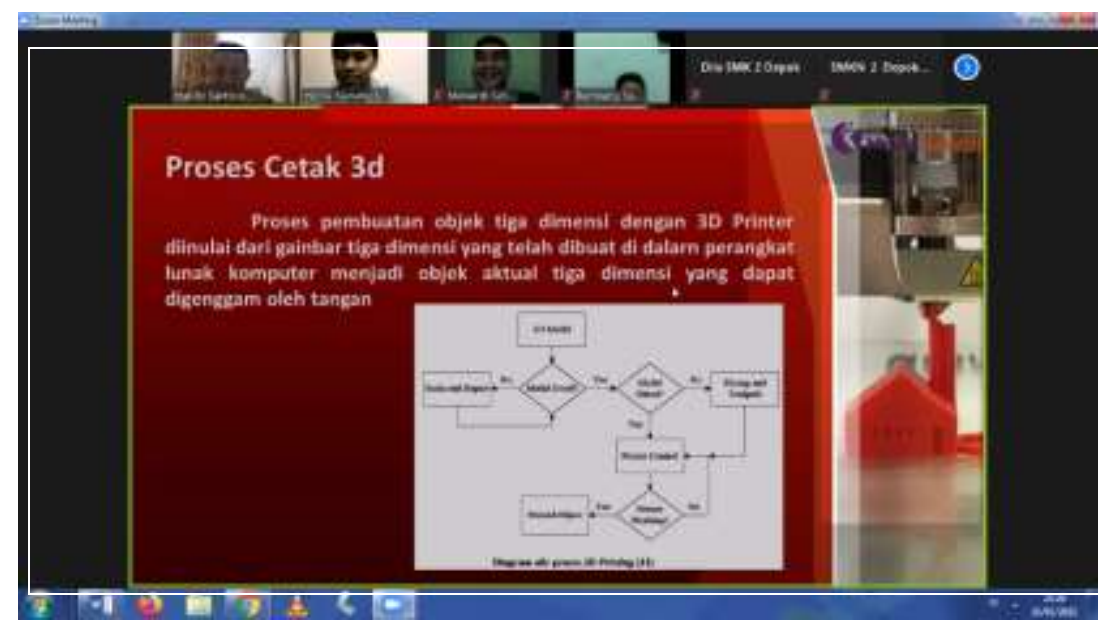

Gambar 5.3 Penyampaian Materi oleh Narasumber 1 (Sumber: screenshoot Penulis) 


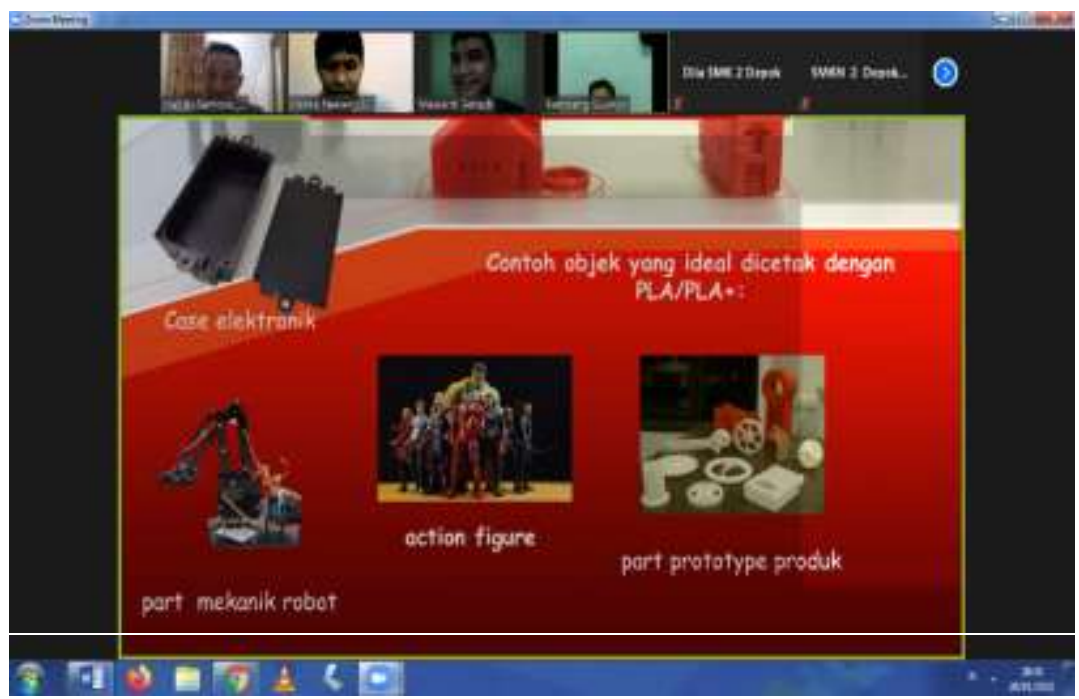

Gambar 5.4 Penyampaian Materi oleh Narasumber 1

(Sumber: screenshoot Penulis)

Selanjutnya Habibi Santoso, S.T., M.T pemateri ke 2 dalam hal ini memberikan penjelasan kepada para peserta pelatihan mengenai pengoperasian materi 3D Printing dalam mencetak produk 3D Printing yang telah di desain.

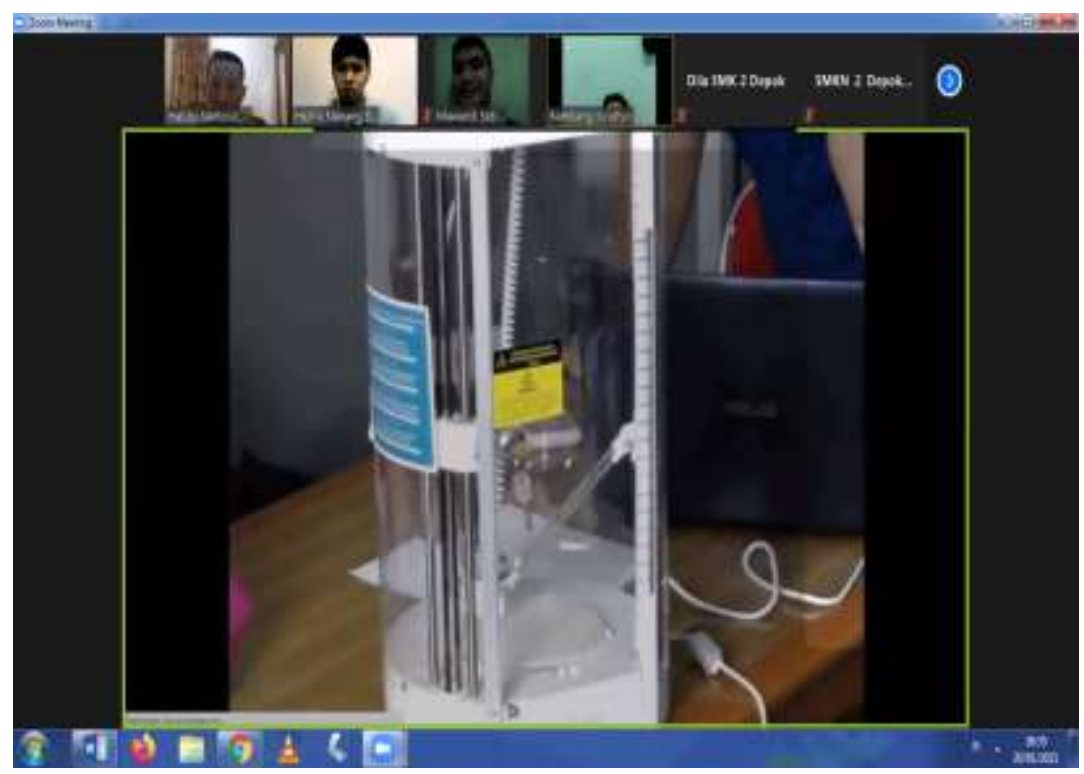

Gambar 5.5 Penjelasan Video Proses Kerja Mesin oleh Narasumber 2 (Sumber: screenshoot Penulis) 


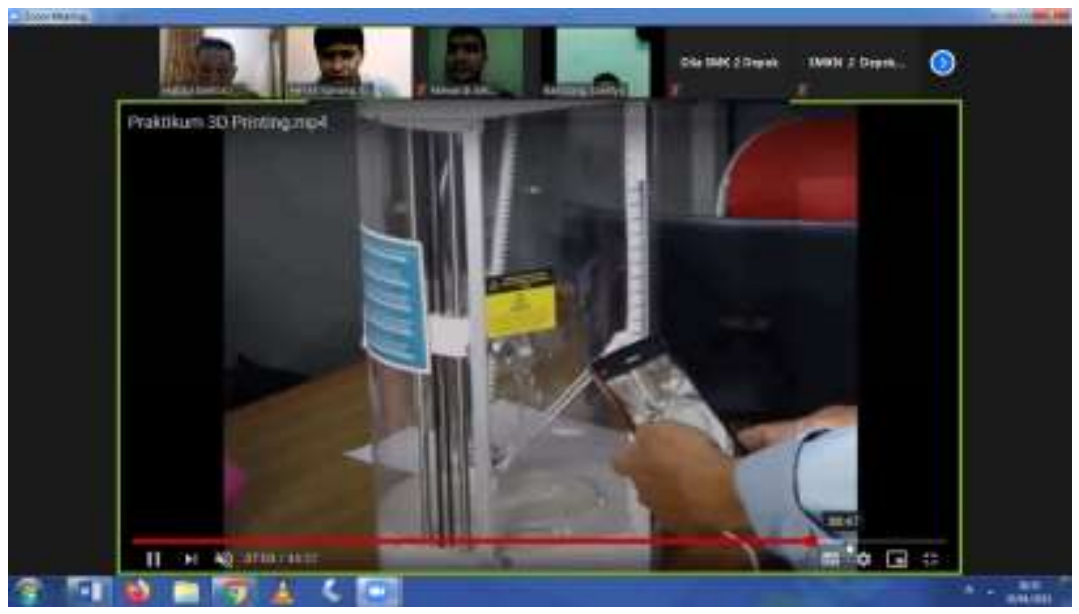

Gambar 5.6. Penjelasan Video Proses Kerja Mesin oleh Narasumber 2 (Sumber: screenshoot Penulis)

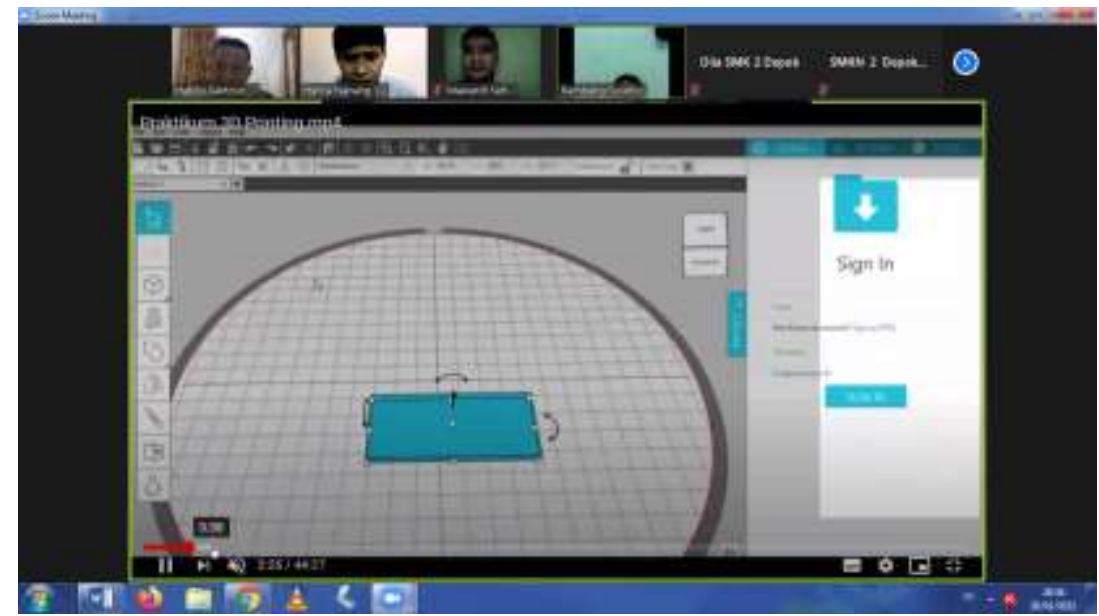

Gambar 5.6. Penjelasan Video Proses Kerja Mesin oleh Narasumber 2 (Sumber: screenshoot Penulis)

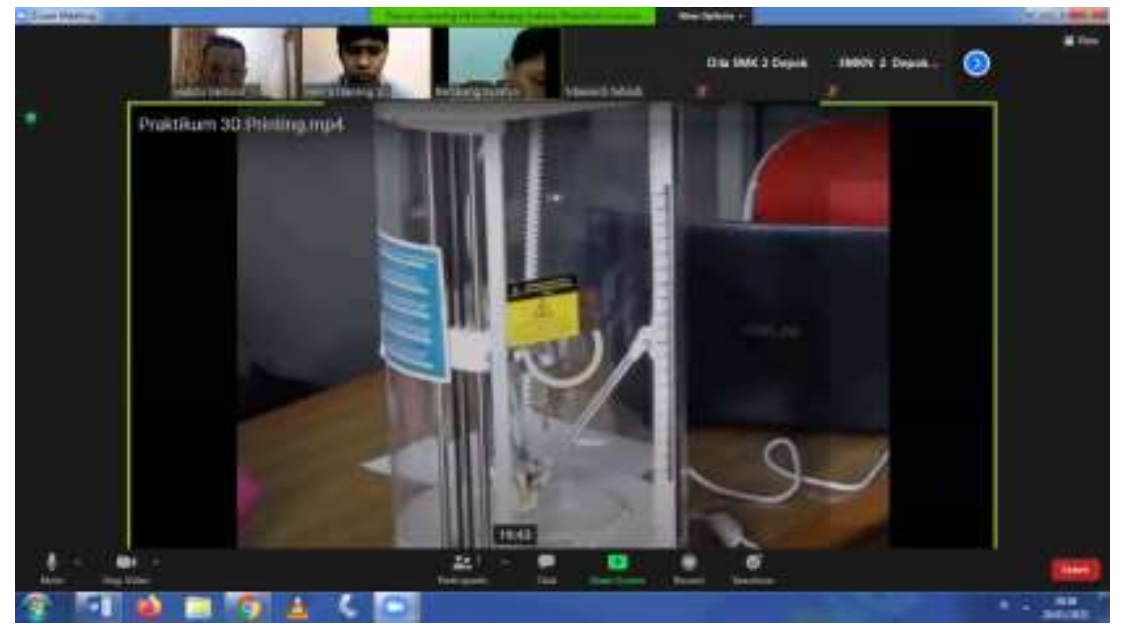

Gambar 5.6. Penjelasan Video Proses Kerja Mesin oleh Narasumber 2 (Sumber: screenshoot Penulis) 


\section{Monitoring dan evaluasi}

Hasil Angket

\section{a. Hasil Angket Awal}

Angket awal digunakan untuk mengetahui seberapa jauh pengetahuan peserta tentang teknologi 3D printing. Hal ini bertujuan agar narasumber dapat mengetahui tingkatan materi yang akan diberikan tentang 3D Printing.

\section{Apakah saudara tau tentang teknologi 3d Printing}

6 tanggapan
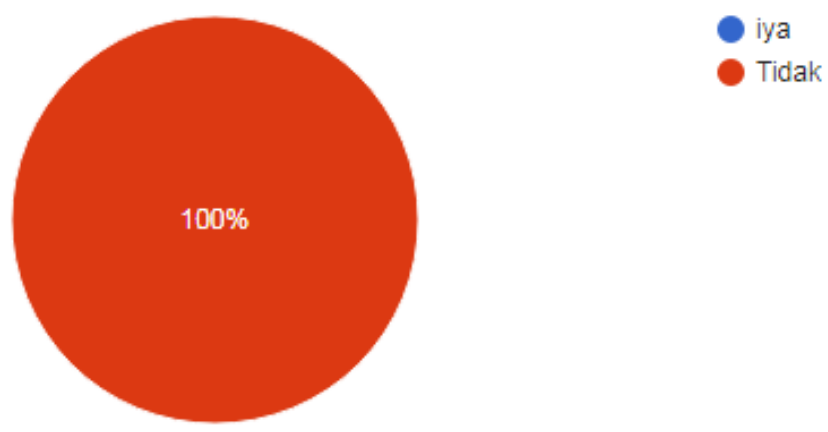

Gambar 5.7 hasil kuesioner awal

Hasil dari angket awal tentang pengetahuan teknologi 3D Printing didapatkan $100 \%$ guru-guru belum mengetahui teknologi mesin 3D Printing

\section{b. Hasil Angket Akhir}

Setelah pelatihan didapatkan hasil angket akhir menunjukan bahwa keberhasilan memberikan pemahaman pengenai teknologi 3D printing dimana para guru-guru merasa ilmu dan pengetahuannya mengenai teknologi salah satunya teknologi 3D printing bertambah setelah mengikuti pelatihan.

Hal tersebut dapat dilihat dari jawaban peserta di bawah ini :

Teknologi 3D printing sangat membantu pendidikan?

6 tanggapan

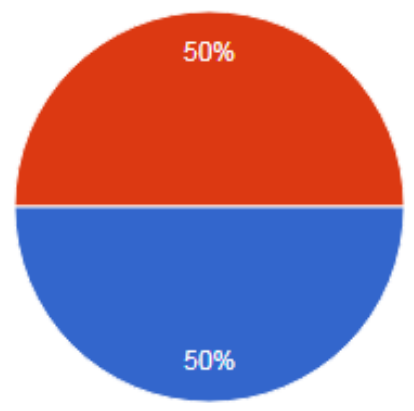


Gambar 5.7 hasil kuesioner

Teknologi 3D Printing sangat memberikan manfaat

6 tanggapan

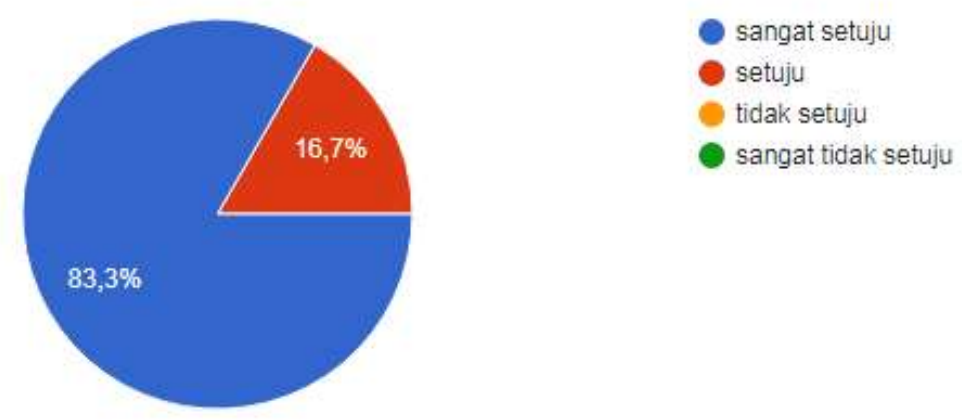

Gambar 5.8 hasil kuesioner manfaat

Fungsi dari mesin 3D Printing sudah dipahami

6 tanggapan

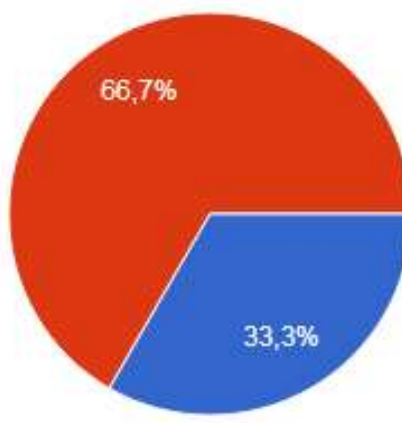

sangat setuju

setuju

tidak setuju

sangat tidak setuju

Gambar 5.9 hasil kuesioner fungsi 3D printing

Setelah pelatihan didapatkan hasil angket akhir pertanyaan mengenai teknologi printing menunjukan bahwa keberhasilan memberikan pemahaman pengetahuannya mengenai teknologi 3D printing bertambah. Hal tersebut dapat dilihat dari jawaban peserta dari dari segi kebermanfaatan $83,3 \%$ setuju dan 16,7 tidak setuju, dari tingkat kepahaman peserta menjawab $66,7 \%$ dan $33,3 \%$ tidak setuju

\section{Kendala yang dihadapi atau masalah lain}


Habibi Santoso, Pelatihan 3D Printing...

Kendala yang dihadapi pada kegiatan Pengabdian Kepada Masyarakat ini adalah masa pandemic yang mengakibatkan kegiatan tidak dapat dilaksanakan secara langsung sehingga pelaksanaan dilakukan secara online dengan menggunakan zoom.

\section{SIMPULAN DAN SARAN}

Pelaksanaan pada kegiatan pengabdian masyarakat kali ini dilakukan secara daring/online dalam bentuk Webinar dengan diskusi, tanya jawab, dan praktek. Angket awal digunakan untuk mengetahui seberapa jauh para peserta guru memiliki pengetahuan tentang teknologi 3D printing. Hasilnya $100 \%$ guru-guru belum mengetahui teknologi mesin 3D Printing

Setelah pelatihan didapatkan hasil angket akhir menunjukan bahwa keberhasilan memberikan pemahaman pengetahuannya mengenai teknologi 3D printing bertambah. Hal tersebut dapat dilihat dari jawaban peserta dari dari segi kebermanfaatan $83,3 \%$ setuju dan 16,7 tidak setuju, dari tingkat kepahaman peserta menjawab 66,7\% dan 33,3\% tidak setuju.

Dari hasil kegiatan pengabdian kali ini terlihat sangat berdampak positif terhadap guruguru di sekolah. Saran secara umum kepada kepala sekolah agar dapat menyediakan mesin 3D printing demi kelancaran proses belajar mengajar dan untuk para guru-guru selalu meningkatkan pemanfaatan teknologi sebagai alat bantu dalam proses pembelajaran agar proses pembelajaran lebih berkualitas.

\section{UCAPAN TERIMA KASIH}

Tim penulis mengucapkan terima kasih kepada seluruh pihak yang telah bersedia menjadi mitra pengabdian masyarakat ini dan juga pengelola Jurusan Teknik Grafika, sehingga kegiatan pengabdian ini dapat terlaksana dengan baik.

\section{DAFTAR RUJUKAN}

Agris, S. (2017). Pengaruh Parameter Proses Ektrusi 3d Printer Terhadap Sifat Mekanis Cetak Komponen Berbahan Filament PLA (Poly Lactide Acid). Jurnal Teknika STTKD, 4(2), 1-5.

Arthaya.B dan Fransiscus.H. 2015. Eksplorasi Kemampuan dan Kapasitas Mesin 3D Printing dalam Pengembangan Modul Rakitan dan Komponen Uji. Lembaga Penelitian dan Pengabdian Kepada Masyarakat Universitas Katolik Parahyangan

Kumara. S. P, S.Ds., M.A., Ulin. R. S. (2018). Pemanfaatan Teknologi 3D Printing Dalam Proses Desain Produk Gaya Hidup. Prosiding SENSITEK STMIK

Kusuma, I.E. 2016. Pengembangan Model Bisnis Berbasis Teknologi 3d Printer DenganPendekatan Product Service System (PSS). Tesis: Major Of Industrial Ergonomic And Safety Department Of Industrial Engineering Faculty Of Industrial Technology Institut Teknologi Sepuluh Nopember Surabaya

Pristiansyahl. Hasdiansah dan Sugiyarto. (2019). Optimasi Parameter Proses 3D Printing FDM Terhadap Akurasi Dimensi Menggunakan Filament Eflex. Jurnal Teknologi Manufaktur, 11(1)

Setiawan, A. Pengaruh Parameter Proses Ektrusi 3d Printer Terhadap Sifat Mekanis Cetak Komponen Berbahan Filament Pla (Poly Lactide Acid). Jurnal Teknika STTKD 4(2)

Shahrubudin, N., Lee, T.C., \& Ramlan, R. (2019). An Overview on 3D Printing Technology: Technological, Materials, and Applications. Procedia Manufacturing , 35 (2019) 1286-1296

Silaen, B dkk. 2019. Analisis Komparasi Model 3 Dimensi Fotogrametri Rentang Dekat Terhadap Cetakan 3 Dimensi Dengan Alat Cetak Raise3d N2 Plus. Jurnal Geodesi Universitas Diponegoro $8(1)$ 